\title{
THIAMINE IN FISH AND ITS DEGRADATION DURING THERMAL PROCESSING OF SALTED-BOILED FISH
}

\author{
Suparno"), S.W. Hanson ${ }^{* * *}$ and A.J. Rosenthal ${ }^{* * *}$
}

\begin{abstract}
The existence of different forms of thiamine in the flesh of rainbow trout (Salmo gairdneri) and their losses during thermal processing have been investigated. Free thiamine, thiamine pyrophosphate, and protein-bound thiamine were found in the fish muscle. The average total thiamine content was $270 \mu \mathrm{g} \%$. The largest proportion was found as pyrophosphate ester $(80 \%)$ and the remaining smaller proportions were as free- and protein-bound forms (approximately $10 \%$ each). The thermal degradation rate of the total thiamine in fish was high, due mainly to the higher proportion of thiamine pyrophosphate which degraded more quickly than the other two forms. There was an indication that thiamine pyrophosphate and protein-bound thiamine were converted into free thiamine before they were finally degraded during the heating.
\end{abstract}

KEYWORDS: Thiamine degradation, fish, thermal processing.

\section{INTRODUCTION}

Thiamine (Vitamin B1) has been more widely studied in relation to heat treatment than many other nutrients in food. Consequently, the pathway of thiamine degradation by heat under different conditions, including the mechanism of the chemical reactions involved, has been largely known for some years (Dwivedi and Arnold, 1973). Thiamine degradation by other treatments such as gamma ray, UV light irradiation and microwave energy have also been studied (Thomas et al., 1981; Goldblith et al., 1968).

There are numerous factors influencing the thermal degradation of thiamine. These include temperature, time, $\mathrm{pH}$, electrolyte system (buffer system), heavy metals, concentration of electrolytes (the salt effect), non-electrolytes (such as protein and carbohydrate), forms of thiamine and their concentrations, oxidation-reduction system, and moisture content (Farrer, 1955). The effect of $\mathrm{pH}$ is the most important factor determining the stability of this vitamin during heating. At low $\mathrm{pH}$ (below 4) thiamine is very stable even at relatively high temperatures, but in slightly alkaline conditions considerable loss can occur.
Thiamine degradation in foods has received great attention for several reasons. Being the most heat unstable nutrient, its loss during heat treatment has significant nutritional consequences. On the other hand, its characteristic of susceptibility to heat has made it a good index of a given thermal treatment. Therefore the kinetic degradation data of thiamine may be used as an index of the efficacy of a thermal process (Stumbo, 1973; Mulley et al., 1975). Thiamine degradation has also an important role in the production of volatile flavour compounds. These compounds can be produced by heating, UV irradiation and Maillard-type reactions (Buttery et al., 1984; Hartman et al., 1984; van Dort et al., 1984)

In spite of a wide range of studies on this vitamin in many foods, relatively little attention has been given to fish products. The present study is aimed at investigating all possible thiamine forms and their levels in fish flesh especially in relation to thermal processing. The information obtained is not only useful for nutritional assessment of these products, but it may also be required for designing optimum nutrient retention during thermal processing. Potential applications are in fish canning and traditional processing of boiled fish (Suparno, 1988).

\footnotetext{
*) Research Institute for Marine Fisheries, Jakarta, Indonesia

**) Superior Software Ltd. Leeds. UK

***) School of Biological \& Molecular Sciencies, Oxford Brookes University, Oxford. UK
} 


\section{MATERIALS AND METHODS}

\section{Materials}

(a) Fish. Rainbow trout (Salmo gairdneri) was used for the experiment. They were freshly harvested from local farms in Louth, Lincolnshire (UK) in mid October 1987. The size of fish used was in the range of 300-350 g weight.

(b) Chemicals. All reagents used were of analytical reagent grade and preparation of all the solutions are described in A.O.A.C. (1980). Fungal amylase was obtained from Miles Laboratory Inc., Germany.

\section{Methods}

(a) Sample Preparation: Fresh fish meat was chopped and macerated. The meat was used to study methods of thiamine analysis and the determination of thiamine contents in the fresh fish as the raw material for heat processing.

To study the effect of heat treatment on thiamine loss, the dressed fish were salted in $25 \%$ salt solution for two hours. Then the fish were wrapped in aluminium foil and heated in a laboratory steam retort. Heating conditions were set at $121^{\circ} \mathrm{C}$ for heating times of $0,10,20,30,40,50$ and 60 minutes. Cooked fish meat samples were prepared by the same procedure as that for fresh meat samples.

(b) Thiamine Analysis. The AOAC method (1980) was used as a basic method for thiamine analysis. For determination of free thiamine and thiamine pyrophosphate, the accuracies and reproducibilities of the developed methods were checked by a spiking technique using standard compounds. The analysis of the three different forms of thiamine is shown schematically in Fig. 1.

Digestion of Sample: Approximately 2-3 g of sample was transferred into a $100 \mathrm{ml}$ test tube and $25 \mathrm{ml} 0.1 \mathrm{M}$ hydrochloric acid solution added. The sample was digested in boiling water for 30 minutes. After being cooled, the $\mathrm{pH}$ of the solution was checked. If higher than $\mathrm{pH} 4.0$, the solution was discarded. The solution was transferred into a $100 \mathrm{ml}$ volumetric flask and made up to volume with distilled water. The solution was divided into 2 parts. One part (A) was used for total thiamine (free thiamine, thiamine-pyrophosphate and protein-bound thiamine) determination, and another part (B) was used for free plus bound thiamine determination.

Determination of Total Thiamine: The digested solution (A) was supplemented with $15 \%$ sodium acetate solution until the $\mathrm{pH}$ reached 4.5-5.0 and then $5 \mathrm{ml}$ of $10 \%$ amylase solution was added. This solution was incubated in a water bath at $50-55^{\circ} \mathrm{C}$ for three hours. The time and temperature for optimum enzymic hydrolysis were further investigated.

Determination of Protein-Bound Thiamine: $2-3 \mathrm{~g}$ of sample was weighed and transferred to a homogenising vessel. After addition of $20 \mathrm{ml}$ of $15 \%$ trichloroacetic acid (TCA) solution, the sample was filtered through an ashless and acid resistant filter paper. The precipitate was washed with two $10 \mathrm{ml}$ portions of $15 \%$ TCA solution and digested with hydrochloric acid solution as described above $(\mathrm{C})$ and protein-bound thiamine estimated.

\section{RESULTS AND DISCUSSION}

\section{Developed Method of Analysis}

Several methods of determination of thiamine, for different types of samples, with different methods and instruments are available (e.g. A.O.A.C., 1980; Brubacher et al., 1985; Mickelsen and Yamamoto, 1958). The present study has developed a relatively simple and accurate method for thiamine determination in fish products. The method is essentially an improvement of the AOAC (1980) method. It should be mentioned that thiamine determination in foods has generally meant total thiamine. Since thiamine in food can occur in three different forms (i.e. freepyrophosphate ester, and protein-bound forms) with different susceptibilities to heat treatment, it is important to develop methods of analysis for each. 
As shown in Fig. 1, the first step in total thiamine analysis is acid digestion to liberate thiamine from the cell tissues. Purification of the digested solution is commonly employed to remove interference by passing the solution through a column containing resin. This time consuming work can be omitted by treating the digested solution with sufficient crystalline $\mathrm{KCl}$ to form a saturated solution while maintaining the $\mathrm{pH}$ around 4.0. The clear solution obtained does not show any interference from other compounds when scanned through the spectrofluorometer at wavelength regions near the thiochrome fluorescence wavelength.

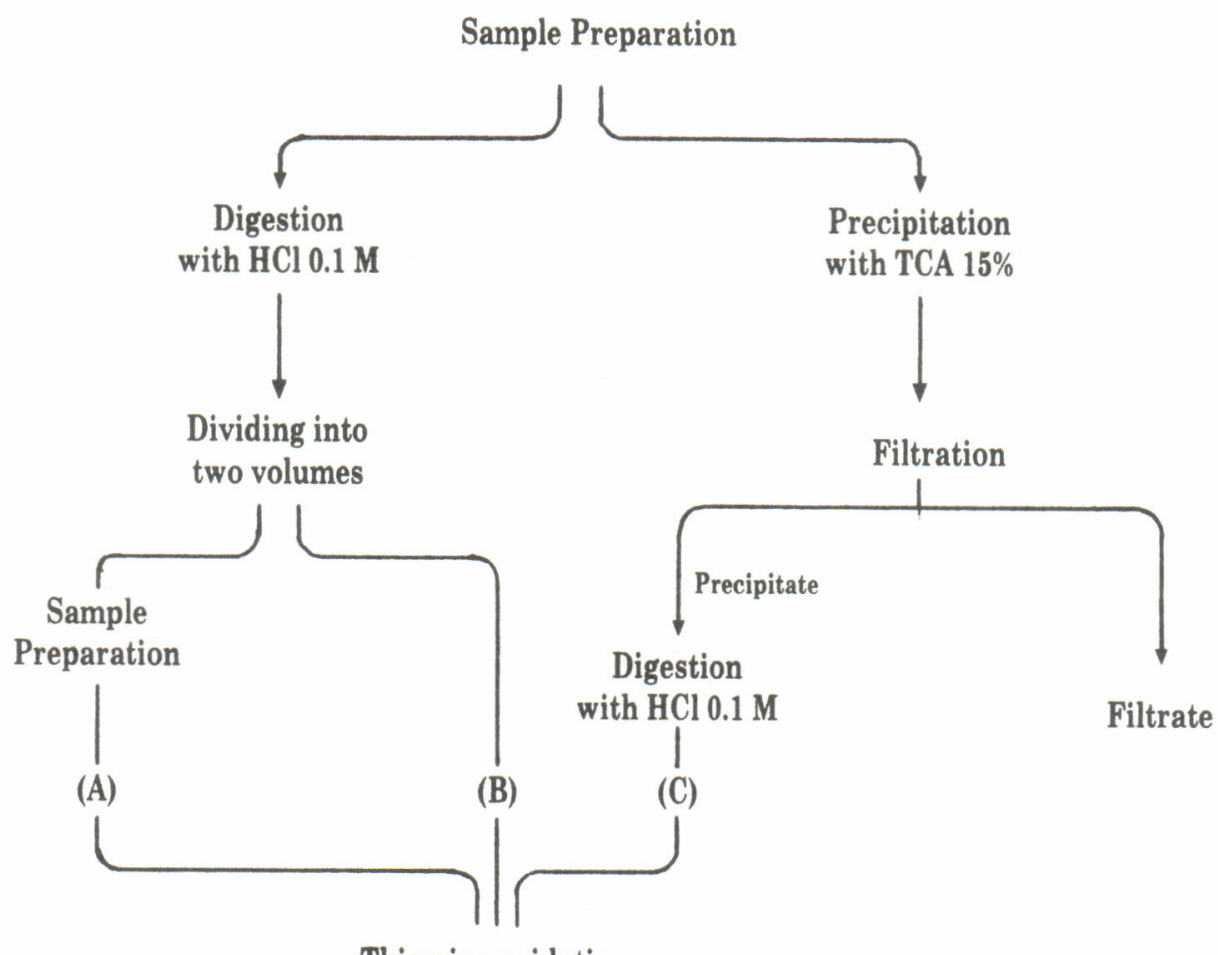

Thiamine oxidation

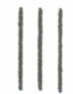

Thiochrome extraction

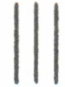

Fluorescence reading

(A, B and C)

Note: $\mathrm{A}=$ total thiamine, $\mathrm{B}=$ free- + protein-bound thiamine, $\mathrm{C}=$ protein-bound thiamine

Figure 1. Determination of different forms of thiamine contents in fish.

Protein-bound thiamine is commonly found in milk, yet it is rarely found in other foods (Farrer, 1955). It is easily converted into the free form during acid digestion. For this reason determination of free thiamine in many foods may include protein-bound thiamine. Determination of pro- tein-bound thiamine is easily prepared by precipitation with trichloroacetic acid (TCA) solution prior to acid digestion. On the other hand, in the determination of thiamine pyrophosphate, which is based on the determination of total thiamine, its accuracy depends significantly on the effective- 
ness of the enzyme hydrolysis. The optimum for this condition should therefore be investigated.

The optimum $\mathrm{pH}$ for enzyme activity was initially discovered during a 3 hour incubation period at a temperature of $50^{\circ} \mathrm{C}$ as shown in Fig. 2. It appeared that $\mathrm{pH} 5.7$ was the optimum. At higher $\mathrm{pH}$ values, a steady reduction of recoveries was observed. This may be partly due to thermal destruction at this elevated temperature.

Similarly optimum temperature was found to be approximately $45^{\circ} \mathrm{C}$ as shown in Fig. 3. Combining these optimum factors $(\mathrm{pH}$ and temperature) for 3 hours incubation time, the recoveries obtained were relatively low (70-73\%). An attempt

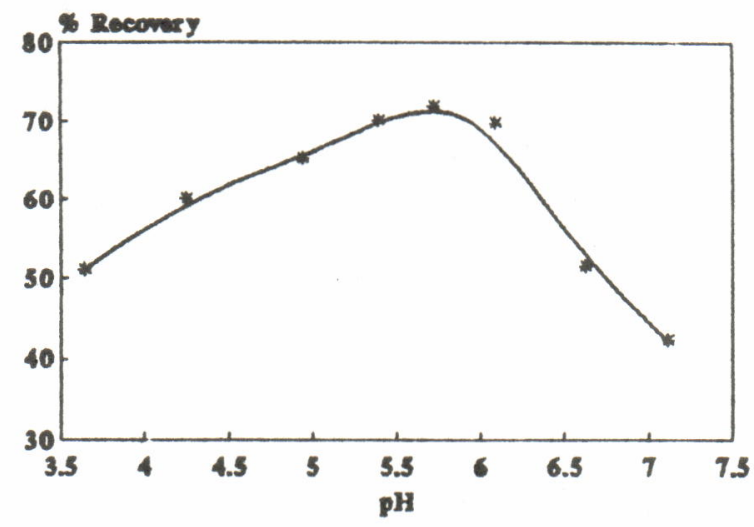

Figure 2. Enzyme activity at different $\mathrm{pH}$ values (incubation temp. $50^{\circ} \mathrm{C}$ for $3 \mathrm{hrs}$ ).

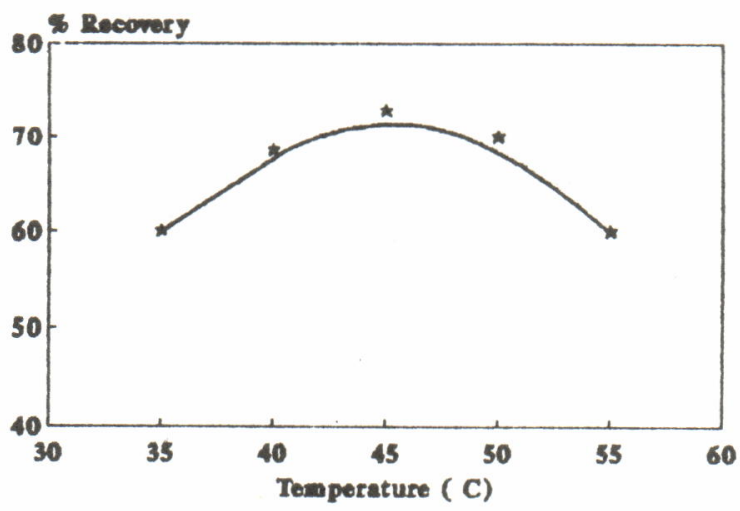

Figure 3. Enzyme activity at different temperatures (incubation time for $3 \mathrm{hrs}$ at pH 5.7).

to increase recovery by increasing the incubation time showed insignificant improvement. Much higher recoveries (between 93-95\%) were obtained by enzymic hydrolysis carried out overnight at a temperature range between $30-35^{\circ} \mathrm{C}$ with a $\mathrm{pH}$ level of 4.5. Lowering temperature and $\mathrm{pH}$ levels for hydrolysis from the previous optimum condi. tions was intended to reduce microbial growth and high temperature effects. Both conditions of hydrolysis may be used in the determination of the thiamine by taking account the recovery figures in their calculations.

\section{Thiamine Contents in Fish}

The results of the investigation show that all three forms of thiamine were present in the fish muscle of rainbow trout, as shown in Table 1 . It is obvious that the majority of thiamine present in the fish muscle is in the form of thiamine pyrophosphate (approximately $80 \%$ ) and at equal level of $10 \%$ each as free thiamine and proteinbound thiamine. It suggests that fish rely on thiamine as a coenzyme in their metabolism, which is similar to that commonly found in terrestrial animals (Higashi, 1961). 
It is obvious that the thiamine pyrophosphate contents in fish muscle vary less than the other forms. It is suspected that the thiamine pyrophosphate is maintained at about this level for biological activity (metabolism) of the fish. The free thiamine may be readily converted to thiamine pyrophosphate to maintain this level to the degree required for metabolism.

However, the roles of the other forms of thiamine in fish are not known. The level of thiamine content in fish depends also on the presence of thiaminase originating from the muscle tissue or from bacteria, or by other antithiamine factors. Thus storage of raw fish or the degree of freshness may influence reduction of the thiamine level in muscle tissues. It should be noted, howev- er, that some enzymes in the flesh or in bacteria may also synthesise this vitamin.

\section{Thiamine Losses}

Instability of thiamine to heat treatment has been proved. The destruction of thiamine during processing salted-boiled fish is shown in Fig. 4. In this experiment, free and bound thiamines were not determined individually as they were present in much lower levels than the thiamine pyrophosphate. The lower concentration of thiamine at the initial heating time compared to the level for fresh fish meat is due to liquor release by the salting process before heating as well as thermal effects during retort come-up heating time.

Table 1. Different forms of thiamine contents in Rainbow Trout muscle $(\mu \mathrm{g} \%)$.

\begin{tabular}{ccccc}
\hline Fish No. & TPP & FT & PBT & TT \\
\hline \multirow{2}{*}{1} & 216 & 28 & 40 & \\
& $(79.70 \%)$ & $(10.30 \%)$ & $(14.80 \%)$ & 271 \\
2 & 217 & 39 & 34 & \\
& $(74.80 \%)$ & $(13.40 \%)$ & $(11.70 \%)$ & 290 \\
3 & 220 & 25 & 15 & 260 \\
& $(84.60 \%)$ & $(9.60 \%)$ & $(5.70 \%)$ & \\
4 & 205 & 19 & 21 & 245 \\
& $(83.70 \%)$ & $(7.70 \%)$ & $(8.60 \%)$ & \\
5 & 226 & 30 & 24 & 280 \\
& $(80.70 \%)$ & $(10.70 \%)$ & $(8.60 \%)$ & \\
Means & 216.8 & 28.2 & 26.8 & 269.2 \\
S.D. & $(80.70 \%)$ & $(10.34 \%)$ & $(9.88 \%)$ & \\
C.V. & 7.66 & 7.33 & 10.08 & 17.48 \\
\hline
\end{tabular}

Note: TPP $=$ thiamine pyrophosphate FT $=$ free thiamine $;$ PBT $=$ protein-bound thiamine; $\mathrm{TT}=$ total thiamine

It has been found that liquor releases contributed by heavy salting for 2 hours is estimated $5.6 \%$ and thermal effect is about $11 \%$ from the dressed fish weight (Suparno, 1988). The liquor release is suspected to carry a major proportion of this soluble vitamin from fish muscle tissues at the initial heating time compared to the effect of direct thermal degradation. About $33 \%$ of thiamine was lost due to salting and thermal effects in this period. The amounts of liquor released during subsequent heating periods were relatively small. The major contribution to thiamine losses during the remaining periods was therefore mainly due to thermal degradation. 
As shown in Fig. 4, thiamine pyrophosphate destruction was rapid during early heating and then slowly declined. On the other hand, the rate of degradation for total thiamine was more constant during the entire heating period. Interestingly, free thiamine and protein-bound thiamine accumulated during heating for about 30 minutes before their levels dropped again. This fact suggests that thiamine pyrophosphate was partly converted to free thiamine during heating. Thiamine pyrophosphate is thought to be more vulnerable to heat than free thiamine, although other findings are in disagreement on this (Farrer, 1955).

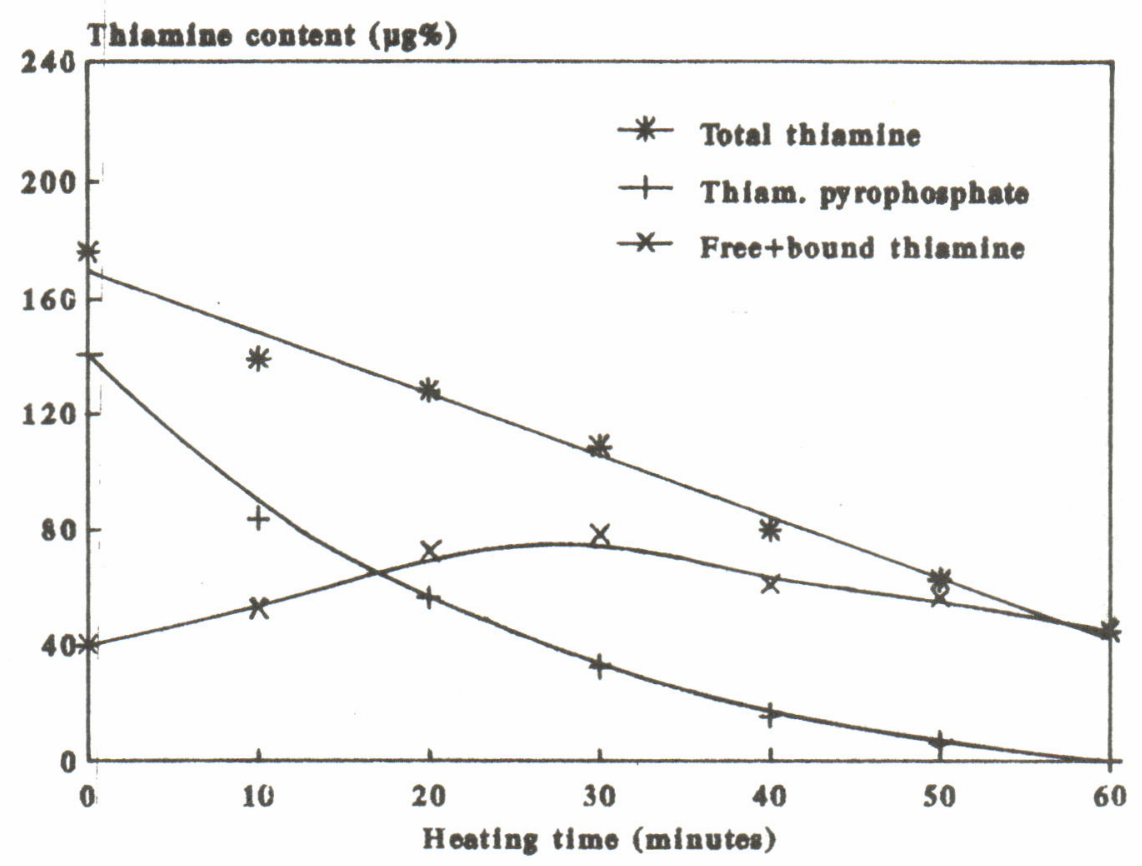

Figure 4. Thermal degradation of different forms of thiamine in fish.

Protein bound thiamine may also be converted to free thiamine before it is degraded, even though this form is considered more stable than others. Stability of protein-bound thiamine to heat treatment has also been shown in the present experiment. After heating for 50 minutes, no thiamine pyrophosphate was detected. Thus, by heating beyond 50 minutes, thiamine in the flesh exists as free and protein-bound forms. Since free thiamine is less stable than protein-bound thiamine, most probably the latter is more predominant in the heated flesh.

\section{CONCLUSION}

(a) Fish muscle contains three forms of thiamine, i.e. free, pyrophosphate ester and protein-bound forms. Thiamine pyrophos- phate constitutes the largest (80\%) portion of thiamine present in fish muscle, and is believed to be associated with biological activity of the animal.

(b) It has been proved that the pyrophosphate ester is the most thermally vulnerable and the protein-bound is the least thermally vulnerable form of thiamine. The thiamine pyrophosphate is completely destroyed by heating the fish at $121^{\circ} \mathrm{C}$ for 60 minutes. During heating, the ester is partly con. verted into the free form before finally being degraded.

\section{REFERENCES}

A.O.A.C. 1980. Official Methods of Analysis. Ed. W. Horwitz. Association of Official Analytical Chemist, Washington D.C., $13^{\text {th }}$ edition. 
Brubacher, G., Muller-Mulot, W. and Southgate, D.A.T. 1985. Methods for the determination of vitamins in Food. Elsevier Applied Science Publishers.

Buttery, R.G., Haddon, W.F., Seifert, R.M. and Turnbaugh, J.G. 1984. Thiamine odor and Bis (2-methyl-3-furyl) disulfide. Journal of Agriculture and Food Chemistry, 32, 674-676.

Dwivedi, B.K. and Arnold, R.G. 1973. Chemistry of thiamine degradation in food products and model systems: A Review. Journal of Agriculture and Food Chemistry, 21, 54-60.

Farrer, K.T.H. 1955. The thermal destruction of vitamin B1 in foods. In: Advances in Food Research. Volume 6. Ed. E.M. Mrak and G.F. Stewart. Academic Press, New York.

Goldblith, S.A., Tannenbaum, S.R. and Wang, D.I.C. (1968). Thermal and $2450 \mathrm{Mhz}$ microwave energy effect on the destruction of thiamine. Food Technology, 29, 379-382. Hartman, G.J., Carlin, J.T. Scheide, J.D. and Ho, C.T. 1984. Volatile products formed from the thermal degradation of thiamin at high and low moisture levels. Journal of Ariculture and Food Chemistry, 32, 1015-1018.

Hartman, G.J., Carlin, J.T., Scheide, J.D. and Ho, C.T. 1984. Volatile products formed from the thermal degradation of thiamin at high and low moisture levels. Journal of Ariculture and Food Chemistry, $32,1015-1018$
Higashi, H. 1961. Vitamins in fish with special reference to edible parts. In: Fish as Food. Ed. G. Borgstrom. Pp. 411-486. Academic Press, New York.

Michelsen, O. and Yamamoto, R.S. 1958. Methods for the determination of thiamine. In: Methods of Biochemical Analysis. Vol. VI, Interscience Publishers, Inc, New York.

Mulley, E.A., Stumbo, C.R. and Hunting, W.M. 1975 Thiamine: A chemical index of the sterilization efficacy of thermal processing. Journal of Food Science, 50, 1312-1317.

Suparno 1988. Studies on improved methods for processing salted-boiled fish and changes in nutrients and quality during thermal processing. Ph.D. Thesis. School of Food Studies. Humberside College, UK.

Stumbo, C.R. 1973. Thermobacteriology in Food Processing. $2^{\text {nd }}$ edition. Academic Press, New York.

Thomas, M.H., Atwood, B.M., Wierbicki, P. and Taub, I.A. 1981. Effect of radiation and conventional processing on the thiamine content of pork. Journal of Food Science, 46, 824-828.

Van Dort, H.M., van der Linde, L.M., de Rijke, D. 1984. Identification and synthesis of new odour compounds from photolysis of thiamine. Journal of Agriculture and Food Chemistry, 32, 454-457. 